\title{
Characterization of New TRPM8 Modulators in Pain Perception
}

\author{
Carmen De Caro ${ }^{1,2}$, Claudia Cristiano ${ }^{1}{ }^{\circledR}$, Carmen Avagliano ${ }^{1}$, Alessia Bertamino ${ }^{3}$, \\ Carmine Ostacolo ${ }^{1}$ (), Pietro Campiglia ${ }^{3}$ (), Isabel Gomez-Monterrey ${ }^{1}$, Giovanna La Rana ${ }^{1}$, \\ Oreste Gualillo ${ }^{4}$ (D), Antonio Calignano ${ }^{1}$ and Roberto Russo ${ }^{1, *}$ \\ 1 Department of Pharmacy, University of Naples Federico II, 80131 Naples, Italy; \\ carmen.decaro@unina.it (C.D.C.); cla.cristiano@gmail.com (C.C.); carmen.avagliano@gmail.com (C.A.); \\ carmine.ostacolo@unina.it (C.O.); imgomez@unina.it (I.G.-M.); gilarana@unina.it (G.L.R.); \\ calignan@unina.it (A.C.) \\ 2 Department of Science of Health, School of Medicine and Surgery, University of Catanzaro, \\ 88100 Catanzaro, Italy \\ 3 Department of Pharmacy, University of Salerno, 84084 Fisciano, Italy; abertamino@unisa.it (A.B.); \\ pcampiglia@unisa.it (P.C.) \\ 4 SERGAS (Servizo Galego de Saude) and IDIS (Instituto de Investigación Sanitaria de Santiago), The NEIRID \\ Group (Neuroendocrine Interactions in Rheumatology and inflammatory Diseases), Santiago University \\ Clinical Hospital, 15706 Santiago de Compostela, Spain; oreste.gualillo@sergas.es \\ * Correspondence: roberto.russo@unina.it
}

Received: 18 September 2019; Accepted: 6 November 2019; Published: 7 November 2019

\begin{abstract}
Background: Transient Receptor Potential Melastatin-8 (TRPM8) is a non-selective cation channel activated by cold temperature and by cooling agents. Several studies have proved that this channel is involved in pain perception. Although some studies indicate that TRPM8 inhibition is necessary to reduce acute and chronic pain, it is also reported that TRPM8 activation produces analgesia. These conflicting results could be explained by extracellular $\mathrm{Ca}^{2+}$-dependent desensitization that is induced by an excessive activation. Likely, this effect is due to phosphatidylinositol 4,5-bisphosphate (PIP2) depletion that leads to modification of TRPM8 channel activity, shifting voltage dependence towards more positive potentials. This phenomenon needs further evaluation and confirmation that would allow us to understand better the role of this channel and to develop new therapeutic strategies for controlling pain. Experimental approach: To understand the role of TRPM8 in pain perception, we tested two specific TRPM8-modulating compounds, an antagonist (IGM-18) and an agonist (IGM-5), in either acute or chronic animal pain models using male Sprague-Dawley rats or CD1 mice, after systemic or topical routes of administration. Results: IGM-18 and IGM-5 were fully characterized in vivo. The wet-dog shake test and the body temperature measurements highlighted the antagonist activity of IGM-18 on TRPM8 channels. Moreover, IGM-18 exerted an analgesic effect on formalin-induced orofacial pain and chronic constriction injury-induced neuropathic pain, demonstrating the involvement of TRPM8 channels in these two pain models. Finally, the results were consistent with TRPM8 downregulation by agonist IGM-5, due to its excessive activation. Conclusions: TRPM8 channels are strongly involved in pain modulation, and their selective antagonist is able to reduce both acute and chronic pain.
\end{abstract}

Keywords: TRPM8; orofacial pain; neuropathic pain; local application; systemic administration

\section{Introduction}

Transient receptor potential (TRP) channels are a group of ion channels belonging to the voltage-gated superfamily, including voltage-gated $\mathrm{K}^{+}, \mathrm{Na}^{+}$, and $\mathrm{Ca}^{2+}$ channels and cyclic 
nucleotide-gated channels [1]. TRP channels are expressed in many tissues and cells, with different functions in neurobiology and grouped into several subfamilies. Among them, TRPM subfamily is the most enigmatic [2], with TRPM8 one of the best-studied members. TRPM8 is a non-selective cation channel activated by noxious, cold, and chemical compounds such as menthol and icilin [3,4]; it is expressed in a subpopulation of cold-sensitive dorsal root ganglion (DRG) neurons, in sensory nerves, and it has also been found in the bladder and male genital tract $[5,6]$. Several studies indicate the contribution of this channel in the pathophysiology of cold allodynia and nociception [7]. The role of TRPM8 in modulating pain perception has been largely evaluated by means of TRPM8-deficient $\left(\right.$ Trpm $\left.8^{-/-}\right)$mice [8,9]. Moreover, an increase of TRPM8 expression in different animal models such as neuropathy induced by oxaliplatin [10] and by streptozotocin-induced diabetes [11] is documented, confirming its role in the somatic sensory nervous system response [12] and underlining its function in pain management [13]. In support of these findings, we have recently shown that novel TRPM8 inhibitors remarkably reduced cold and mechanical allodynia in acute and chronic pain models [14]. These results clearly indicate that TRPM8 inhibition has an analgesic effect; however, other studies showed in some animal models of nerve injury, that peripheral and central activation of TRPM8 is also followed by analgesia [15]. Moreover, functional and anatomical studies also demonstrated a direct role of TRPM8 in inflammation; however, this needs to be further elucidated [16]. Several other studies showed apparently controversial results. For example, selective TRPM8 inhibitors were able to reduce allodynia and hyperalgesia, suggesting that this channel significantly contributes to neuropathic pain modulation $[14,17]$. On the other hand, some other evidence has established the analgesic properties of TRPM8 agonists [18,19]. Many theories have been proposed to explain these conflicting data; among these, the hypothesis that has found greater consensus is the negative modification of the receptor. It is widely known that the hyperstimulation of a membrane receptor can induce an important alteration of its functionality, leading to inactivation. The TRPM8 receptor-channel can undergo desensitization, probably due to a depletion of the second messenger, PIP2, which influences both the channel activity and the membrane potentials $[20,21]$. Therefore, the development of antagonists would be preferred for a possible therapeutic exploitation; however, the study of selective TRPM8 agonists is to be considered in order to better understand the complex phenomenon of desensitization [17].

To better understand the role of this channel in pain perception, in this study, we tested two compounds, an agonist and an antagonist of TRPM8 receptor (Chart 1), previously evaluated in vitro [22], in either acute or chronic pain models using both systemic and local routes of administration.
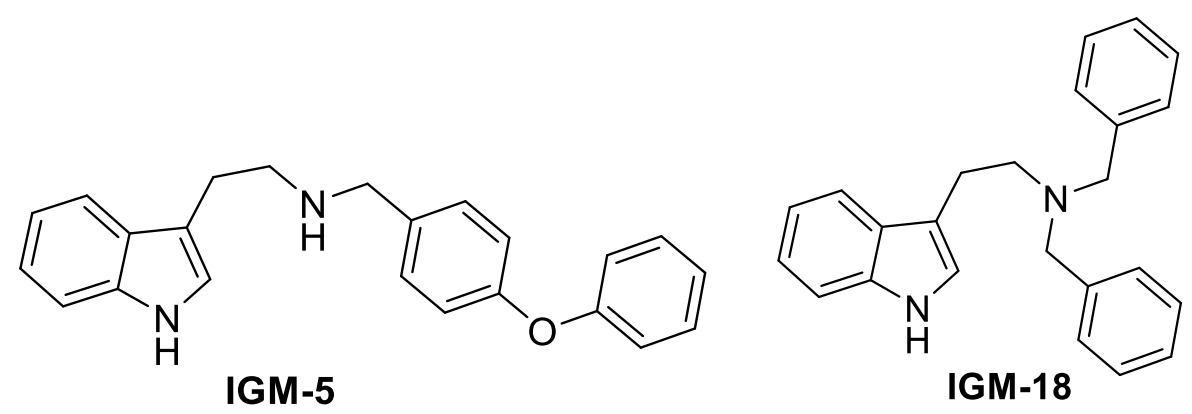

Chart 1. Molecular structures of IGM-5 and IGM-18, TRPM8 agonist and antagonist, respectively.

\section{Results}

\subsection{Effect of IGM-18 on Formalin-Induced Orofacial Pain}

Formalin-induced neurogenic inflammation is a typical pain model used for evaluating the antinociceptive properties of drugs. Injection of formalin produces a significant edema, with long-lasting secondary hypersensibility, from 12 up to $72 \mathrm{~h}$. In the present work, formalin was injected into the 
upper lip region of rats in order to produce orofacial allodynia, as previously done [14]. Then, the effect of IGM-18 on this formalin induced orofacial pain model was evaluated.

We observed that $12 \mathrm{~h}$ after formalin injection into the upper lip region of rats, the vehicle-treated group showed a significant reduction of contact time by mechanical stimulus (Figure 1, white bar; ${ }^{\circ \circ 0} p<0.001$ vs. the respective basal group) compared to sham rats. Systemic IGM-18 pre-treatment ( $1 \mathrm{~h}$ before) decreased formalin-induced pain in a dose-dependent manner: Indeed, at $1 \mathrm{mg} / \mathrm{kg}\left({ }^{*} p<0.05\right)$ and $10 \mathrm{mg} / \mathrm{kg}\left({ }^{* * *} p<0.001\right)$, it significantly reduced the contact time compared to the vehicle group (Figure 1), while no significant effect was observed using doses of 0.1 and $0.3 \mathrm{mg} / \mathrm{kg}$ (Figure 1).

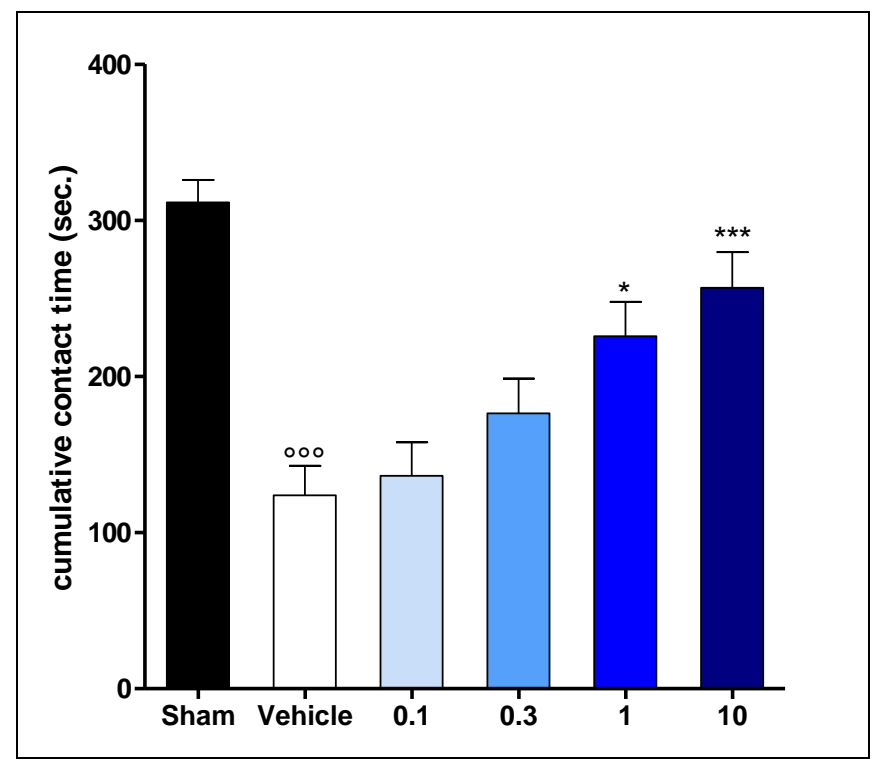

Figure 1. Effect of vehicle and IGM-18 in formalin-induced orofacial pain hypersensibility. After $12 \mathrm{~h}$ from formalin injection, rats were treated with vehicle (white column) and IGM-18 (0.1-10 mg/kg; blue columns); test was done $1 \mathrm{~h}$ following systemic administration. The sham group represents the measurement before formalin injection. The cumulative contact time was counted for $10 \mathrm{~min}$. Data are shown as mean \pm SEM of 6 animals per group. ${ }^{\circ 00} p<0.001$ vs. sham group; ${ }^{*} p<0.05$ and ${ }^{* * *} p<0.001$ vs. vehicle.

\subsection{Effect of TRPM8 Antagonist (IGM-18) in Chronic Constriction Injury (CCI)-Induced Neuropathic Pain}

The CCI model is a commonly used model of neuropathic pain. In this experiment, on day 14 , we evaluated the dose-dependent effect of IGM-18 following a single systemic administration, $1 \mathrm{~h}$ before the measurement of cold sensitivity. The vehicle-treated group showed a significant increase of cold responses compared to the sham group (Figure 2A, white bars; ${ }^{\circ \circ} p<0.001$ ). IGM-18 induced a reduction of allodynia; this effect was statistically significant at the highest doses, 1 and $10 \mathrm{mg} / \mathrm{kg}$ (Figure $2 \mathrm{~A} ;{ }^{* *} p<0.01$ and ${ }^{*} p<0.05$ vs. CCI-vehicle-treated mice), while no activity was observed at the lower doses of 0.1 and $0.3 \mathrm{mg} / \mathrm{kg}$. Subsequently, we evaluated time course using the first active dose, $1 \mathrm{mg} / \mathrm{kg}$. As reported in Figure $2 \mathrm{~B}$, animals treated with the vehicle showed a significant cold allodynia compared to sham mice (Figure $2 \mathrm{~B}$, white bars; ${ }^{\circ \circ} p<0.001$ ), while systemic IGM-18 $(1 \mathrm{mg} / \mathrm{kg})$ administration produced a marked reduction of the number of paw withdrawals at $0.5 \mathrm{~h}$ and $1 \mathrm{~h}$ post-dose (Figure $2 \mathrm{~B} ;{ }^{* *} p<0.01$ and ${ }^{*} p<0.05 \mathrm{vs}$. CCI-vehicle-treated mice); no effect was observed at $3 \mathrm{~h}$ post-dose and on the contralateral (unlighted) paw (data not shown). In another set of CCI experiments, the activity of TRPM8 antagonist following local administration on the paw was tested. Three different doses were used (0.1-1 mg/100 $\mu \mathrm{L} / \mathrm{paw})$. As reported in Figure 3A, animals treated with the vehicle showed a significant cold allodynia compared to sham rats (Figure 3A, white bar; ${ }^{\circ} p<0.01$ vs. sham mice). IGM-18 reduced allodynia in a dose-dependent manner. Indeed, the dose of $0.3 \mathrm{mg} / \mathrm{paw}$ produced a significant antiallodynic effect that became more marked using 
the higher doses of IGM-18 $(1 \mathrm{mg} / 100 \mu \mathrm{L} / \mathrm{paw})$. No effect was observed using the lowest dose $(0.1 \mathrm{mg} / 100 \mu \mathrm{L} / \mathrm{paw})$ (Figure $3 \mathrm{~A} ;{ }^{* *} p<0.01$ and ${ }^{*} p<0.05 \mathrm{vs}$. CCI-vehicle-treated mice). Figure 3B reports the time course $(0.5,1$, and $3 \mathrm{~h}$ after local application) using the first active dose. Local IGM-18 $(0.3 \mathrm{mg} / 100 \mu \mathrm{L} / \mathrm{paw})$ application produced a significant reduction of the number of paw withdrawals at 0.5 and $1 \mathrm{~h}$ post-application (Figure $3 \mathrm{~B} ;{ }^{* *} p<0.01$ and ${ }^{*} p<0.05$ vs. CCI-vehicle-treated mice); no effect was observed at $3 \mathrm{~h}$ post-application.

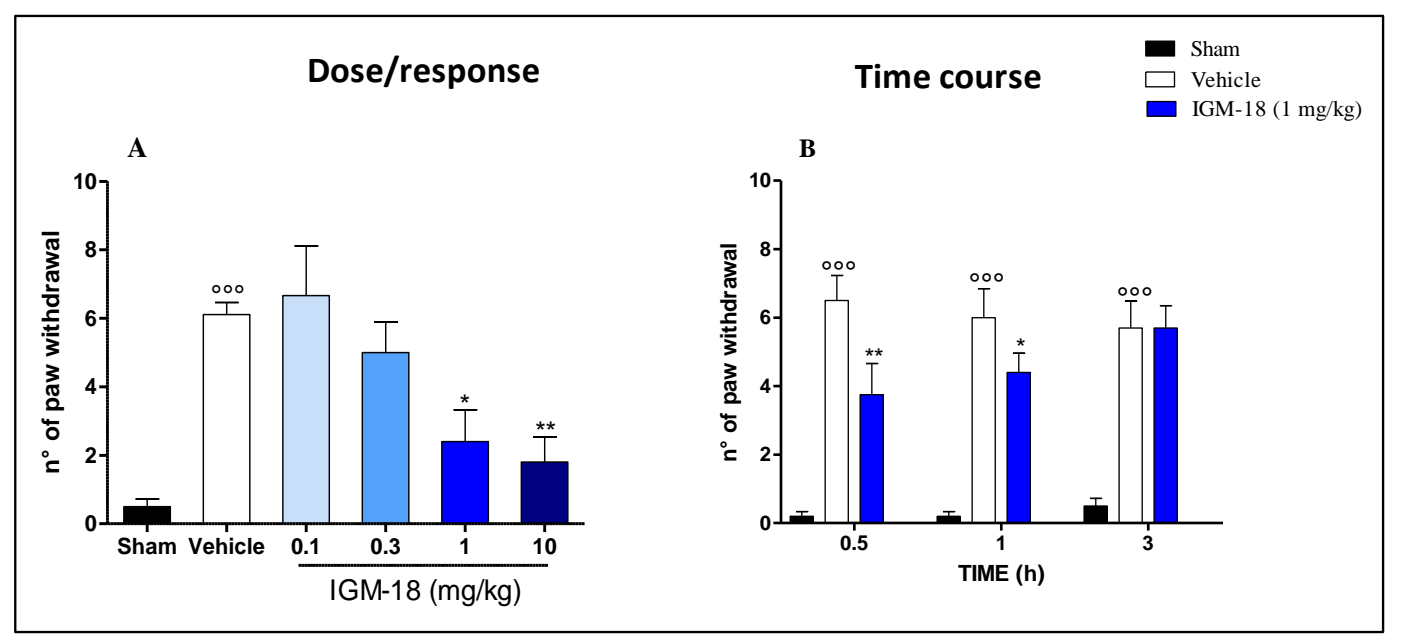

Figure 2. (A) Dose-response effect of IGM-18 (0.1-10 mg/kg/i.p) on CCI-induced neuropathic pain. IGM-18 (blue columns) and vehicle (white column) were administered intraperitoneally on day 14 after ligation, $1 \mathrm{~h}$ before the test. The sham group did not receive ligation (black columns). Data are shown as mean \pm SEM of 6 animals per group. ${ }^{\circ 00} p<0.001$ vs. sham group; ${ }^{*} p<0.05$ and ${ }^{* *} p<0.01$ vs. vehicle. (B) Time course effect of vehicle (white column) and IGM-18 (1 mg/kg; blue columns) following systemic administration. Drug was administered intraperitoneally $0.5,1$, and $3 \mathrm{~h}$ before test. Data are shown as mean \pm SEM of 6 animals per group. ${ }^{\circ \circ 0} p<0.001$ vs. sham group; ${ }^{*} p<0.05$ and ${ }^{* *} p<0.01$ vs. vehicle.

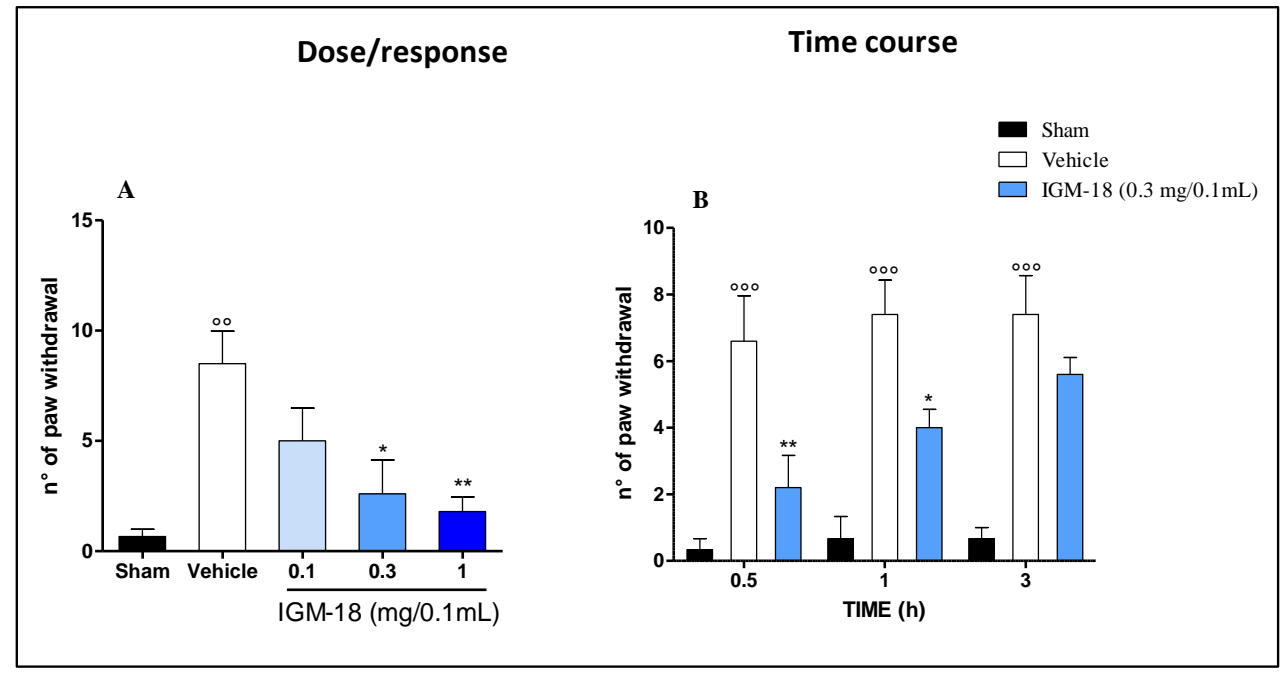

Figure 3. (A) Dose-response effect of IGM-18 (0.1-1 mg/0.1 mL/paw) on CCI-induced neuropathic pain. IGM-18 (blue columns) and the vehicle (white column) were administered locally on day 14 after ligation, $0.5 \mathrm{~h}$ before the test. The sham group did not receive ligation (black columns). Data are shown as mean \pm SEM of 6 animals per group. ${ }^{\circ 0} p<0.01$ vs. sham group; ${ }^{*} p<0.05$ and ${ }^{* *} p<0.01$ vs. vehicle. (B) Time course effect of vehicle (white column) and IGM-18 (0.3 mg/0.1 mL/paw; blue columns) in cold allodynia induced by CCI after local administration. Tests were performed at $0.5,1$, and $3 \mathrm{~h}$ after IGM-18 or vehicle application. Data are shown as mean \pm SEM of 6 animals per group. ${ }^{\circ 00} p<0.001$ vs. sham group; ${ }^{*} p<0.05$ and ${ }^{* *} p<0.01$ vs. vehicle. 


\subsection{Effect of TRPM8 Agonist (IGM-5) on CCI-Induced Neuropathic Pain}

Based on the aforementioned results, we investigated the effects of TRPM8 agonist (IGM-5) local application on the CCI mouse model of cold allodynia. Three different doses were used (0.1-0.3 and $1 \mathrm{mg} / 100 \mu \mathrm{L}$ ). Animals treated with the vehicle showed a significant cold allodynia compared to sham mice (Figure $4 \mathrm{~A}$, white bar; ${ }^{\circ 0} p<0.01$ vs. sham mice). IGM- 5 induced hypersensitivity using the lowest dose $(0.1 \mathrm{mg})$ compared to vehicle-treated mice, while the intermediate and highest doses ( 0.3 and $1 \mathrm{mg}$, respectively) produced a significant reduction of cold responses $\left({ }^{* *} p<0.01\right.$ and $* p<0.05$ vs. vehicle-treated mice). Using only the lowest dose, we measured paw withdrawal numbers after each one of the three consecutive acetone applications (reported in figure as "single phase"). As shown in Figure 4B, acetone failed to produce a significant effect of cold allodynia after the second and the third applications, while a significant increase of numbers of paw withdrawal were detected after the first acetone exposure ( ${ }^{*} p<0.05$ vs. vehicle-treated mice). IGM-5 $(0.1-10 \mathrm{mg} / \mathrm{kg}$ ) was also tested by systemic administration, but no significant effect was observed at all used doses (data not shown).

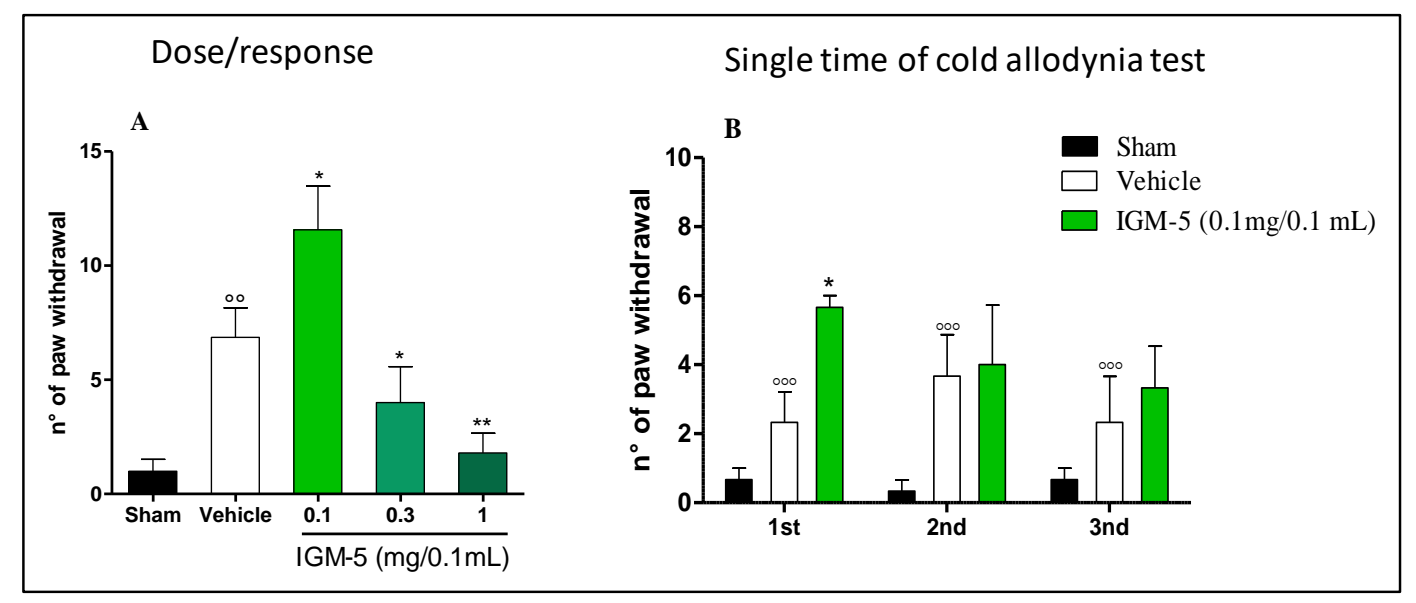

Figure 4. (A) Dose-response effect of IGM-5 (0.1-1 mg/0.1 mL/paw) on CCI-induced neuropathic pain. The vehicle (white column) and IGM-5 (green columns) were administered locally on day 14 after ligation $0.5 \mathrm{~h}$ before the test. The sham group did not receive the ligation (black columns). Data are shown as mean \pm SEM of 6 animals per group. ${ }^{\circ \circ} p<0.01$ vs. sham group; ${ }^{*} p<0.05$ and ${ }^{* *} p<0.01 \mathrm{vs}$. vehicle. (B) Time course effect of the vehicle (white column) and IGM-5 (0.1 mg/0.1 mL/paw; green columns) on cold allodynia induced by CCI after local administration. Allodynia responses were evaluated after the first (1st), the second (2nd), and the third (3nd) acetone application. Data are shown as mean \pm SEM of 6 animals per group. ${ }^{\circ 0 \circ} p<0.001$ vs. sham group; ${ }^{*} p<0.05$ vs. vehicle.

\subsection{Effect of IGM-18 on Icilin-Induced Wet-Dog Shake (WDS)}

Subsequently, we evaluated the ability of TRPM8 antagonist to block the spontaneous wet-dog shake (WDS) induced by icilin. For this propose, IGM-18 was administrated $1 \mathrm{~h}$ before icilin $(1 \mathrm{mg} / \mathrm{kg}$, i.p.) and WDS were recorded for $30 \mathrm{~min}$. In the vehicle-treated group, an average of 127 shakes was counted (Figure 5, white column). The pre-treatment with IGM-18 (1 mg/kg) significantly decreased by $47 \%$ the number of icilin-induced WDS (Figure $4 ;{ }^{* *} p<0.01$ vs. vehicle-treated rats).

\subsection{Effect of TRPM8 Modulators on Body Temperature}

Finally, we evaluated the effects of IGM-18 and the IGM- 5 on body temperature (Tb). The acute treatment with IGM-18 at the highest dose $(10 \mathrm{mg} / \mathrm{kg})$ produced a significant decrease of $\mathrm{Tb}$ at different time points; specifically, of $-1{ }^{\circ} \mathrm{C}$ at $0.5 \mathrm{~h},-0.8^{\circ} \mathrm{C}$ at $1 \mathrm{~h},-1.2^{\circ} \mathrm{C}$ at $2 \mathrm{~h}$, without a significant reduction at $3 \mathrm{~h}$ (Figure $6 \mathrm{~A},{ }^{*} p<0.05 \mathrm{vs}$. vehicle). As expected, intramuscular administration of icilin $(7.5 \mathrm{mg} / \mathrm{kg})$, used as positive control, increased $\mathrm{Tb}$ values with a maximum of $0.6^{\circ} \mathrm{C}, 2$ and $3 \mathrm{~h}$ after treatment (Figure 6B, black square; ${ }^{*} p<0.05$ vs. vehicle group). Similarly, intramuscular administration of 
TRPM8 agonist (IGM-5), used at equimolecular dose of icilin $(8.2 \mathrm{mg} / \mathrm{kg})$, produced a significant increase of Tb; specifically, of $+0.1^{\circ} \mathrm{C}$ at $0.5 \mathrm{~h},+0.8^{\circ} \mathrm{C}$ at $1 \mathrm{~h}$, and $+0.6^{\circ} \mathrm{C}$ at $2 \mathrm{~h}$, while no effect was detectable at $3 \mathrm{~h}$ (Figure $6 \mathrm{~B},{ }^{*} p<0.05$ vs. vehicle group).

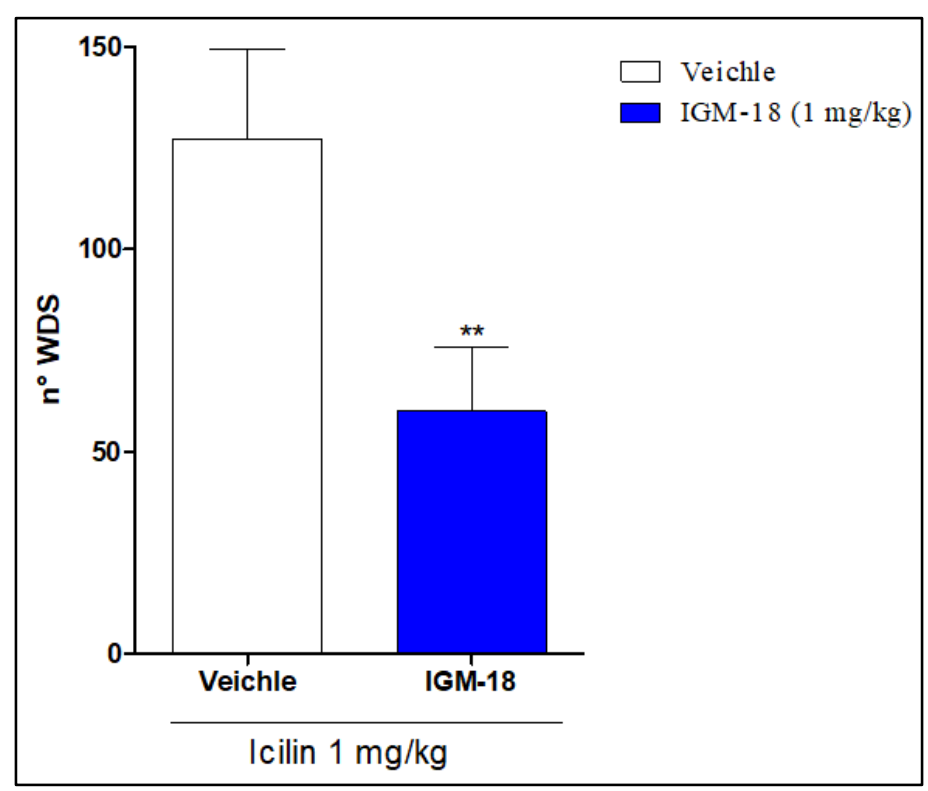

Figure 5. Effect of IGM-18 on icilin-induced wet-dog shake (WDS). Rats were pre-treated with the vehicle (white column) and IGM-18 ( $1 \mathrm{mg} / \mathrm{kg}$; blue column), after $0.5 \mathrm{~h}$ icilin was injected ( $1 \mathrm{mg} / \mathrm{kg}$, i.p.) and the number of WDS were counted for $30 \mathrm{~min}$. Data are shown as mean \pm SEM of 6 animals per group. ${ }^{* *} p<0.01$ vs vehicle group.

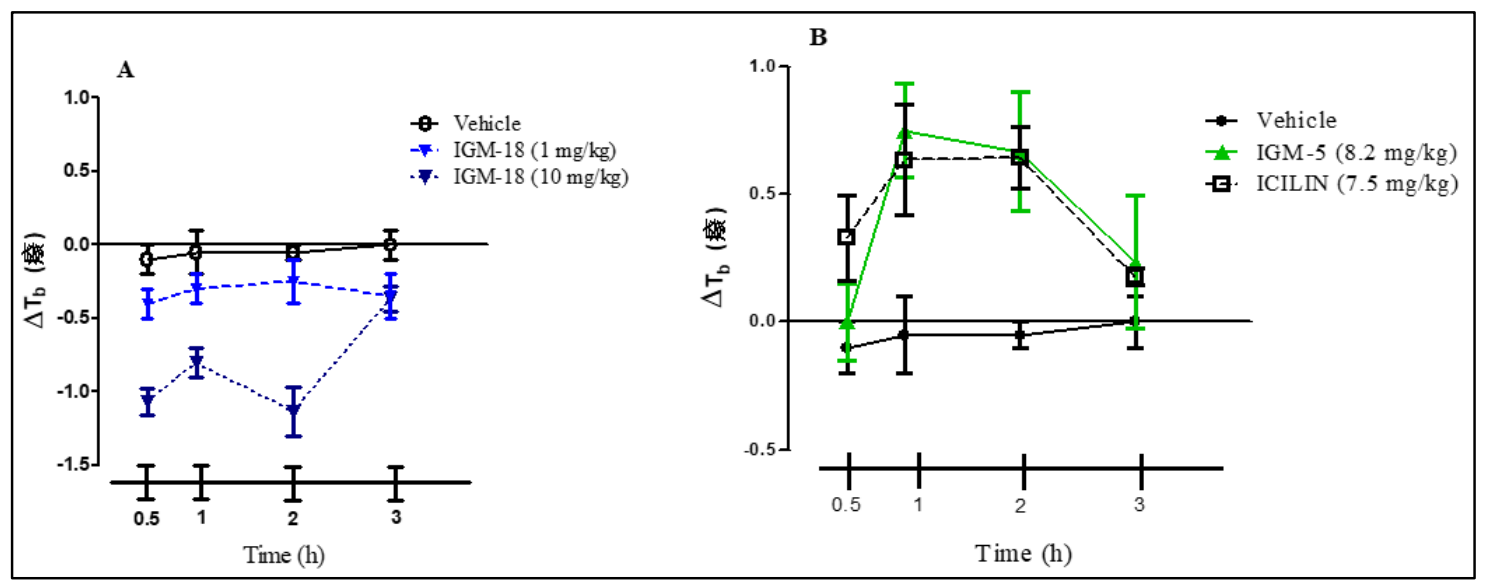

Figure 6. (A) Effect of IGM-18 (1 and $10 \mathrm{mg} / \mathrm{kg}$ ) on body temperature (Tb). Tb was measured at time 0 (before treatment) and $0.5,1,2$, and $3 \mathrm{~h}$ post-drug administration. (B) Effect of Icilin $(7.5 \mathrm{mg} / \mathrm{kg}$ ) and equimolecular dose of IGM-5 Icilin $(8.2 \mathrm{mg} / \mathrm{kg})$ on body temperature $(\mathrm{Tb})$. Tb was measured at time 0 (before treatment) and 1, 2, and $3 \mathrm{~h}$ post-drug administration. Data are shown as mean [differences between temperature after (Tpost dose) and before treatment (Tbasal)] \pm SEM of 6 animals per group.

\subsection{Selectivity Studies}

Several other TRP channels have been described as involved in pain perception, particularly TRPV1 and TRPA1 that share high homology with TRPM8. This is because the prototypical TRPM8 agonist menthol [23,24], and some canonical TRPM8 antagonists such as BCTC [25], are also able to modulate TRPV1 and TRPA1 channels. Thus, selectivity represents one of the main issues in the development of TRPM8 modulators [26]. On the other side, it has also been reported that NaV1.7 channels are involved in acute mechanical, thermal, and chemical noxious stimuli perception. For 
these reasons, IGM-18 and IGM- 5 were examined for their selectivity by further investigation using fluorescence imaging. As shown in Table 1, the two compounds proved to be highly selective for TRPM8, since IGM-5 was mostly inactive on the three selected targets (with a really weak antagonism on NaV1.7). Similarly, IGM-18 was inactive as antagonist on the selected targets, showing only a weak agonistic activity on TRPA1 with a ten-fold selectivity for TRPM8.

Table 1. Profiling of the compounds on human Nav1.7, TRPA1 and TRPV1ion channels.

\begin{tabular}{|c|c|c|c|c|c|c|}
\hline \multirow{2}{*}{$\begin{array}{c}\text { Compound } \\
\text { Agonist mode }\end{array}$} & \multicolumn{2}{|c|}{ NaV1.7 } & \multicolumn{2}{|c|}{ TRPA1 } & \multicolumn{2}{|c|}{ TRPV1 } \\
\hline & Signal at Max ${ }^{a}$ & $\mathrm{EC}_{50}$ & Signal at Max ${ }^{a}$ & $\mathrm{EC}_{50}$ & Signal at Max ${ }^{a}$ & $\mathrm{EC}_{50}$ \\
\hline IGM-5 & 0.11 & inactive & 14.603 & inactive & 0.4130 & inactive \\
\hline IGM-18 & 0.133 & inactive & 58.176 & $3.9 \mathrm{M}$ & -1.923 & inactive \\
\hline Venatridine & 100 & $2.70 \mathrm{M}$ & NC & NC & $\mathrm{NC}$ & $\mathrm{NC}$ \\
\hline AITC & $\mathrm{NC}$ & $\mathrm{NC}$ & 100 & $1.15 \mathrm{M}$ & $\mathrm{NC}$ & NC \\
\hline Capsaicin & $\mathrm{NC}$ & NC & NC & $\mathrm{NC}$ & 100 & $22 \mathrm{nM}$ \\
\hline \multicolumn{7}{|l|}{ Antagonist mode } \\
\hline IGM-5 & -41.25 & $>10 \mathrm{M}$ & -29.88 & inactive & -29.88 & inactive \\
\hline IGM-18 & -19.23 & inactive & -51.69 & inactive & -7.47 & inactive \\
\hline Tetrodotoxin & -100 & $9.2 \mathrm{nM}$ & NC & $\mathrm{NC}$ & $\mathrm{NC}$ & $\mathrm{NC}$ \\
\hline HC-030031 & $\mathrm{NC}$ & $\mathrm{NC}$ & -100 & $20.7 \mathrm{M}$ & $\mathrm{NC}$ & NC \\
\hline Capsazepine & NC & $\mathrm{NC}$ & $\mathrm{NC}$ & NC & -100 & $98 \mathrm{nM}$ \\
\hline
\end{tabular}

\section{Discussion}

The discovery of the transient receptor potential cation channels in primary sensory neurons has changed our understanding about pain perception; in particular, regarding cutaneous temperature detection. It is well known that TRPM8 is expressed by a small population of cold-sensitive sensory neurons and is activated at low temperatures and by the cooling compound menthol or icilin $[3,5]$. TRPM8 has also been involved in the painful hypersensitivity that is a worrying symptom in inflammation and neuropathy. A large body of studies has demonstrated that TRPM8 antagonists are effective in reducing thermal and mechanical hyperalgesia, suggesting for this channel an important role in pain perception $[8,14,17]$. Therefore, it would be greatly helpful to patients with acute and chronic pain to have a compound able to control these symptoms. Here, we tested two new TRPM8 modulators, IGM-5 and IGM-18, a selective agonist and antagonist, respectively, to characterize their contribution on pain, using both systemic and local routes of administration. Conflicting studies have shown that TRPM8 is involved in pain. Data on knockout animals have shown that TRPM8 is involved in cold sensation induced by drop of acetone or chemical compounds, such as menthol and icilin $[9,27,28]$. In this study, we demonstrated that both direct antagonism and the excess dose of agonist, responsible of receptor desensibilization [29], led to the inactivation of this channel that is necessary to decrease pain perception. Indeed, IGM-18, a selective TRPM8 antagonist, following systemic administration or local application, is able to reduce pain. In line with our data, it is reported that TRPM8 is involved in orofacial and visceral (colonic) pain [8,18,30-32], and that its activation by menthol causes irritation in some patients [18]. In our model of orofacial pain induced by formalin, IGM-18 was able to reduce the contact time to mechanical stimulus, confirming the pivotal role of TRPM8 in acute pain [14]. Moreover, TRPM8 antagonist was also used in a chronic pain model, such as neuropathy. It is well known that there is an upregulation of this channel in DRG, after chronic constriction injury of the sciatic nerve (CCI) or chemotherapy-induced neuropathic pain [33,34]. In our protocol, IGM-18 at the dose of $1 \mathrm{mg} / \mathrm{kg}$ reduced cold hyperalgesia induced by CCI, and these effects were significant after both local application and systemic administration. A previous in vitro characterization [22], together with the selectivity assays performed in the present study, highlight the remarkable selectivity of IGM-18 on channel TRPM8. Interestingly, it has been reported that TRPM8 activator reduced mechanical and thermal nociception in the CCI model through a central 
modulation [15], and these analgesic effects are supported by a study using TRPM8 knock-out mice [28]. Moreover, menthol is widely used as a topical analgesic and inhaled antitussive with respiratory counterirritant properties. Menthol and TRPM8-selective agonists have been shown to suppress nocifensive responses to several acute pain stimuli, including capsaicin, acrolein, and acid [18]. Our data showed that systemic IGM-5 administration did not modify paw withdrawal latency in mice that underwent CCI (data not shown). By contrast, local application showed opposite effects, i.e., lower dose-induced pain, while high doses showed a significant antiallodynic activity. This conflicting data could be explained through the alteration of TRPM8 activity, since it has been demonstrated that the activation of this channel is followed by extracellular $\mathrm{Ca}^{2+}$-dependent desensitization, probably due to the PIP2 depletion that leads to the reduction of TRPM8 channel activity, accompanied by a shifting voltage dependence towards more positive potentials $[20,21]$. Overall, it seems likely that TRPM8 is normally expressed in a distinct population of cool-responsive afferents, and also in some nociceptors [3]. Moreover, other behavioral studies using icilin or menthol have also pointed out that agonist activation of TRPM8 may cause sensitization or desensitization/inhibition of responses to mechanical stimuli under naïve conditions [35-37] or after injury [15,18,35]. Furthermore, it has been demonstrated that TRPM8-mediated analgesia was selectively reversed by intrathecal administration of Group II/III mGluR antagonists and mimicked by agonists, and ionophoresis of a Group III mGluR antagonist reversed the inhibitory effect of icilin on sensitized single neurons [15]. In fact, it is possible that the TRPM8 activation produces a modulation of glutamate release, inducing an alteration in pain perception [38,39].

However, given that the aim of a good symptom-controlling drug would be to reduce the hypersensitivity without abolishing normal thermosensation, this may not be a completely undesirable effect. It seems that TRPM8-expressing afferents affect thermoregulatory responses to both chemical and thermal stimuli, although the exact neurological mechanism remains unknown $[40,41]$. Because of this evidence, and reports underling that TRPV1 antagonists have undesired thermoregulatory effects [42], we thought it possible that a TRPM8 modulator would also affect thermoregulation. Indeed, it is suggested that TRPM8 plays a key role in thermoregulation, with the stimulation of skin afferents both with chemical and cooling agonists [40]. Here, we have confirmed that IGM-5 induced an increase in body temperature, as well as icilin, a chemical TRPM8 agonist [43], an effect that is TRPM8-dependent due to the lack of modulation on TRPA1 channels, as shown by in vitro selectivity studies $[3,30]$. By contrast, systemic IGM-18 administration reduced body temperature in a dose-dependent manner, and it is noteworthy that the effective dose of $1 \mathrm{mg} / \mathrm{kg}$ did not produce a significant alteration of body temperature. This suggests that the reduction of pain is due to modulation of pain pathways, without any alteration of body temperature. Further experiments are needed to additionally characterize these two novel TRPM8 channel modulators.

\section{Materials and Methods}

\subsection{Animals}

Behavioral experiments were performed on male Sprague-Dawley rats (300-310 g Charles Rivers-Italy) or male CD1 mice (25-30 g Charles Rivers-Italy). They were housed in the animal care facility of the Department of Pharmacy, University of Naples Federico II. Animals were acclimated to their environment for 1 week and had ad libitum access to standard rodent chow pellets VRF1 (purchased from Special Diet Service-SDS, UK, LBS Biotech) and water. All behavioral tests were performed between 9:00 AM and 1:00 PM, and the animals were only tested once. Procedures involving animals and their care were carried out in conformity with international and national law and policies (EU Directive 2010/63/EU for animal experiments). The procedures reported here were approved by the Institutional Committee on the Ethics of Animal Experiments (CSV) (protocol no. 0084607, date 3 October 2014.) of the University of Naples "Federico II" and by the "Ministero Della Salute", At the end of the experiments, animals were euthanized by $\mathrm{CO}_{2}$ overdose. As suggested by the animal 
welfare protocol, all efforts were made to minimize animal suffering and to use only the number of animals necessary to produce reliable scientific data.

\subsection{Drug Treatments}

During this study, IGM-18 was administered systemically and locally, while IGM- 5 only by local administration (excluding the temperature test, using the local equimolecular by systemic administrations). IGM-5 and IGM-18 in local treatments were solubilized in absolute ethanol and used at dose of $0.1,0.3$, and $1 \mathrm{mg} / 100 \mu \mathrm{L}$ of ethanol and applied on operated paw ( $n=6$ for each experimental group). The vehicle group was treated with absolute ethanol only. During systemic administration, two drugs were dissolved in PEG400 10\% (v/v), TWEEN 80 5\% (v/v), and sterile saline and used at different doses $(0.1,0.3,1$, and $10 \mathrm{mg} / \mathrm{kg})$. The vehicle group was treated with PEG, TWEEN, and sterile saline only.

\subsection{Induction of Orofacial Pain}

Orofacial pain hypersensitivity was performed on rats and was induced by formalin, according to the method described by [44] with some modifications [14]. Briefly, $2.5 \%$ formalin $(0.1 \mathrm{~mL})$ was injected into the upper lip, just lateral to the nose using a $27 \mathrm{G}$ sterile needle mounted on a $1 \mathrm{~mL}$ syringe; the needle was inserted into the lip close to the border between hairy and glabrous skin and advanced up to the hilt towards the vibrissa pad. Thus, the formalin solution spread-out within the upper lip and the rostral half of the vibrissa pad, inducing a stereotypical response characterized by two distinct phases: An initial neurogenic phase (0-3 min) and a second inflammatory phase (10-30 min). Differently from [44], we evaluated pain hypersensitivity by mechanical and cold stimuli developed $24 \mathrm{~h}$ after formalin injection using the Orofacial Stimulation Test (Ugo Basile, Italy).

\subsection{Orofacial Stimulation Test}

The orofacial stimulation test system measures hypersensitivity of the trigeminal area. Initially, animals underwent 5 days of training, utilizing the orofacial stimulation test after a $12 \mathrm{~h}$-period of food deprivation (fasting period). Rats were placed in a standard rat cage with a plastic divider to create two rooms. In the anterior room of the cage, there was an Ugo Basile apparatus with a drinking window for the rat's head to enter and acquire a reward (milk and chocolate) located on the opposing aspect of the drinking window. During the training period, each rat was individually placed in the posterior room for $10 \mathrm{~min}$ to familiarize with its environment; subsequently, the drinking window was opened, and the rat was monitored for $10 \mathrm{~min}$ to allow it to drink the milk and chocolate [45]. On the day of the behavioral assessment, mechanical or thermal stimulation was induced by the insertion of an appropriate module in the drinking window (not present during the training period). During this time, rats received approximately 3-5 stimulations prior to formalin (basal) and 15-20 stimulations $24 \mathrm{~h}$ after formalin injection, for both mechanical and thermal stimulator. Similar to the adaptation training, the mechanical module experiment was preceded by a 12-h fasting period, $10 \mathrm{~min}$ for the rats to familiarize with the testing environment, and a subsequent $10 \mathrm{~min}$ for behavioral assessments.

\subsection{Mechanical Stimulator}

Experiments were performed utilizing the mechanical model hat, which consisted of a cassette with 10 tungsten wires placed $3 \mathrm{~mm}$ apart from each other and $8 \mathrm{~mm}$ from the opening hole to the cassette held to produce a bending force from the drinking window of the apparatus. The animal's face contacted the tungsten wires of the mechanical module as the rat projected its head through the hole in the apparatus in order to drink milk and chocolate located on the exterior aspect of the drinking window. In each experiment, a blind observer activated a stopwatch every time the test rat drank milk and chocolate (also defined as "contact time"); when the test rat moved away from the drinking window, the stopwatch was stopped. Data were generated using the total contact time(s) to mechanical 
stimulus reached in a total testing time of $600 \mathrm{~s}$. Basal data were obtained from the total contact time (reached in a total testing time of $600 \mathrm{~s}$ ) $24 \mathrm{~h}$ before formalin injection.

\subsection{Chronic Constriction Injury (CCI) Model of Neuropathic Pain}

Neuropathic pain behavior was performed on mice and it was induced by ligation of the sciatic nerve, as described previously [46]. Briefly, mice ( $n=6$ each group) were first anesthetized with xylazine $(10 \mathrm{mg} / \mathrm{kg}$, i.p.) and ketamine $(100 \mathrm{mg} / \mathrm{kg}$, i.p.), and the left thigh was shaved and scrubbed with betadine. Then, a small incision in the middle left thigh $(2 \mathrm{~cm}$ in length) was performed to expose the sciatic nerve. The nerve was loosely ligated at two distinct sites (spaced at a 2-mm interval) around the entire diameter of the nerve using silk sutures (7-0). The surgical area was closed and finally scrubbed with betadine. In sham-operated animals, the nerve was exposed but not ligated.

\subsection{Cold Allodynia}

Cold sensitivity was measured as the number of foot withdrawal responses after application of cold acetone on dorsal surface of paw after 14 days from CCI. Individual animals were placed in Plexiglas boxes $(30 \times 30 \times 25 \mathrm{~cm})$, a drop of acetone $(25 \mu \mathrm{L})$ was applied to the dorsal surface of the ligated paw with a syringe connected to a thin polyethylene tube while the animals were standing on a metal mesh. A brisk foot withdrawal response, after the spread of acetone over the dorsal surface of the paw, was considered as a sign of cold allodynia. Three measures of 3 min were done for each paw and expressed in numbers of paw withdrawals. IGM- 5 and IGM-18 were tested after both local application and systemic administration. In systemic administration, doses-response $(0.1-10 \mathrm{mg} / \mathrm{kg})$ and time course $(0.5-3 \mathrm{~h})$ were performed. About local application, the results measured were calculated as full time when the values obtained in all the experimental procedure were measured. For IGM-5, the values obtained during the first, second, and third phases (1st, 2nd, and 3rd) were separately expressed, as reported [29]. Moreover, only for IGM-18, a time course (0.5, 1, and $3 \mathrm{~h})$ after topic application was evaluated.

\subsection{Body Temperature (Tb) Measurement}

Rats were placed into an environmental room maintained at a constant temperature of $21 \pm 0.3^{\circ} \mathrm{C}$ and relative humidity of $55 \pm 2 \%$. The animals were allowed to acclimate for $24 \mathrm{~h}$ before taking the first temperature reading. Body temperature $(\mathrm{Tb})$ was recorded using a rectal probe for rats (Model RAT2, Ugo Basile, Italy), which was inserted approximately $5 \mathrm{~cm}$ from the anus. A digital thermometer (Model BAT-10, Ugo Basile, Italy) was used. Tb was measured before treatment (baseline) and at 0.5, 1, 2, and $3 \mathrm{~h}$ following IGM-18 (10 mg/kg, i.m.), IGM-5 (equimolecular dose of the local dose $8.2 \mathrm{mg} / \mathrm{kg}$, i.m), or icilin $(7.5 \mathrm{mg} / \mathrm{kg}$, i.m) administration.

\subsection{Icilin-Induced "Wet-Dog" Shaking in Rats}

Icilin, a TRPM8 agonist, was used to induce shaking in rats [47]. Rats were first habituated to the testing room for $30 \mathrm{~min}$; afterwards, rats were randomized into treatment groups and treated with the vehicle or TRPM8 antagonist (IGM-18 $1 \mathrm{mg} / \mathrm{kg}$, i.p.). Icilin was administered i.p. at $1 \mathrm{mg} / \mathrm{kg}$ and dissolved in 1\% TWEEN 80. The number of intermittent but rhythmic "wet dog-like" shakes (WDS) of neck, head, and trunk in each animal was counted for a period of $30 \mathrm{~min}$ following icilin administration.

\subsection{Fluorescence Imaging Assays}

The compound profiling study was carried out by AXXAM (Bresso, Italy) using human TRPA1, TRPV1, and Nav1.7 to determine the agonistic or inhibitory effect of the tested compounds on any of the targets. Experiments were performed using the following cell lines: HEK-293 (ATCC, CRL-1573), stably transfected with either hTRPA1 or hNav1.7, and CHO-K1, (ATCC, CCL-61) stably transfected with hTRPV1. 
HEK-293 cells were grown in EMEM (MEM Eagle Earl's salts Balanced Salt Solution), supplemented with $5 \mathrm{~mL}$ of $200 \mathrm{mM}$ Ultra glutamine, $1,5 \mathrm{~mL}$ of 100X Penicillin/Streptomycin, $50 \mathrm{~mL}$ of Fetal Bovine Serum, and $2 \mathrm{~mL}$ of $100 \mathrm{mg} / \mathrm{mL}$ G418. CHO-K1 cells were grown in Dulbecco's modified Eagle's medium-Ham F-12 (DMEM F-12) (1:1) mixture $500 \mathrm{~mL}$ supplemented with $5 \mathrm{~mL}$ of $100 \mathrm{mM}$ Sodium Pyruvate, $25 \mathrm{~mL}$ of $7.5 \%$ Sodium Bicarbonate, $6.5 \mathrm{~mL}$ of $1 \mathrm{M}$ Hepes, $5 \mathrm{~mL}$ of $100 \mathrm{X}$ Penicillin/Streptomycin, $50 \mathrm{~mL}$ of Fetal Bovine Serum, $0.25 \mathrm{~mL}$ of $10 \mathrm{mg} / \mathrm{mL}$ Puromycin, $0.5 \mathrm{~mL}$ of $100 \mathrm{mg} / \mathrm{mL}$ Zeocin. The HEK-293 cells were seeded in 384-well clear bottom black polystyrene walled poly-D-Lys-coated plates (TwinHelix, Rho, Italy), while the CHO-K1 cells in a 384-well clear bottom black walled polystyrene plates, (Thermo Scientific, Waltham, USA). The extracellular solution used was a Standard Tyrode's buffer composed by $130 \mathrm{mM} \mathrm{NaCl}, 5 \mathrm{mM} \mathrm{KCl}, 2 \mathrm{mM} \mathrm{CaCl} 2,5 \mathrm{mM} \mathrm{NaHCO}, 1 \mathrm{mM}$ $\mathrm{MgCl} 2,20 \mathrm{mM}$ HEPES, pH 7.4, and sterilized by filtration. Compound dilution was performed in 96-well U bottom plates (Thermo Scientific), then compounds were transferred into 384-well V bottom polypropylene barcoded plates (Thermo Scientific). The experimental activities were performed using the EMCCD camera FLIPRTETRA (MDC). For TRPA1 and TRPV1 selectivity assays, cells were seeded at 10,000 cells/well in $384 \mathrm{MTP}$ in complete medium ( $25 \mu \mathrm{L} /$ well). Then, $24 \mathrm{~h}$ after seeding, culture medium was removed and cells were loaded with $20 \mu \mathrm{L} /$ well of $0.5 \mathrm{X}$ calcium sensitive dye (Fluo- 8 $\mathrm{NW}$ ) in assay buffer. Plates were incubated for $1 \mathrm{~h}$ at room temperature in the dark and then injected at $10 \mu \mathrm{L} /$ well of test compounds and controls at $3 X$ concentration with the FLIPRTETRA, recording the signal of the emitted fluorescence. A second injection of $15 \mu \mathrm{L} /$ well of $3 X$ reference activator (at $\sim$ EC80) with the FLIPRTETRA was performed, recording the signal of the emitted fluorescence. For Nav1.7 selectivity assays, cells were seeded at 15,000 cells/well following the same protocol described above and using a fluorescent membrane potential sensitive dye (Blue) as readout. The reference agonists used were allylisothiocianate for TRPA1 (AITC, 100-0.0316 $\mu \mathrm{M}$ concentration interval, EC80 $=3 \mu \mathrm{M})$, Capsaicin for TRPV1 $(300-0.1 \mathrm{nM}$ concentration interval, EC80 = $100 \mathrm{nM})$, and Veratridine for Nav1.7 $(300-0.1 \mu \mathrm{M}$ concentration interval, EC $80=10 \mu \mathrm{M})$. The reference antagonists used were HC-030031 for TRPA1 $(100-0.0316 \mu \mathrm{M}$ concentration interval, EC80 $=100 \mu \mathrm{M})$, Capsazepine for TRPV1 $(3.16-0.001 \mu \mathrm{M}$, concentration interval, EC80 = 3.16 $\mu \mathrm{M})$, and Tetrodotoxin (TTX) for Nav1.7 $(10-0.00316 \mu \mathrm{M}$ concentration interval, EC $80=10 \mu \mathrm{M})$.

Compounds were tested against the targets at eight concentrations, intraplate with quadruplicate data points. In order to obtain the eight concentration points of the dose-response curve, a serial dilution protocol in $100 \%$ DMSO was performed for each compound by using a 96 U bottom MTP as support. To obtain the 3-fold concentration to be injected on the cell plate, compounds were further diluted in assay buffer, and the final DMSO amount was $0.1 \%$. In order to generate quadruplicate data points, each well of the 96 MTP was then replicated into four wells of a 384 MTP for each compound and for each concentration to be tested. The dilution plates were produced on the same day of the experiment. For data quality and data analysis, the Screener 14.0 software (Genedata, Basel, $\mathrm{CH}$ ) was used.

\subsection{Statistical Analysis}

In vivo data are presented as mean \pm SEM. In the orofacial test, data are presented as cumulative contact time (sec). In CCI experiments, DPA data are presented as paw withdrawal threshold (g), cold allodynia data are presented as number of paw withdrawals. The significance of differences between groups was determined by a one-way repeated measurements ANOVA, followed by a Bonferroni's post-hoc test. For the body temperatures, the data are expressed as differences between temperature obtained after injection (Tpost dose) and temperature before treatment (Tbasal); results are presented as $\triangle \mathrm{Tb} \pm \mathrm{SEM}$. The significance of differences between groups was determined by a one- or two-way repeated measurements ANOVA, followed by a Bonferroni's post-hoc test.

Author Contributions: Methodology in vivo, C.D.C., C.C., G.L.R. and R.R.; conceptualization A.B., C.O.; data curation, C.A. and R.R.; writing-original draft preparation, R.R.; review and editing, C.O., O.G; supervision, P.C., I.G.-M. and A.C. 
Funding: This research received no external funding.

Acknowledgments: We would like to thank Gabriella Aviello for English editing, and Giovanni Esposito and Angelo Russo for animal care and assistance in the Department of Pharmacy of University of Naples.

Conflicts of Interest: The authors declare no conflicts of interest.

\section{References}

1. Jan, L.Y.; Jan, Y.N. A superfamily of ion channels. Nature 1990, 345, 672. [CrossRef] [PubMed]

2. Moran, M.M.; Szallasi, A. Targeting nociceptive transient receptor potential channels to treat chronic pain: Current state of the field. Br. J. Pharmacol. 2018, 175, 2185-2203. [CrossRef] [PubMed]

3. Neuhausser, W.M.; Julius, D. Identification of a cold receptor reveals a general role for TRP channels in thermosensation. Nature 2002, 416, 52-58.

4. Weyer-Menkhoff, I.; Lötsch, J. Human pharmacological approaches to TRP-ion-channel-based analgesic drug development. Drug Discov. Today 2018, 23, 2003-2012. [CrossRef]

5. Peier, A.M.; Moqrich, A.; Hergarden, A.C.; Reeve, A.J.; Andersson, D.A.; Story, G.M.; Earley, T.J.; Dragoni, I.; McIntyre, P.; Bevan, S.; et al. A TRP channel that senses cold stimuli and menthol. Cell 2002, 108, 705-715. [CrossRef]

6. Stein, R.J.; Santos, S.; Nagatomi, J.; Hayashi, Y.; Minnery, B.S.; Xavier, M.; Patel, A.S.; Nelson, J.B.; Futrell, W.J.; Yoshimura, N.; et al. Cool (TRPM8) and hot (TRPV1) receptors in the bladder and male genital tract. J. Urol. 2004, 172, 1175-1178. [CrossRef]

7. Caspani, O.; Zurborg, S.; Labuz, D.; Heppenstall, P.A. The contribution of TRPM8 and TRPA1 channels to cold allodynia and neuropathic pain. PLoS ONE 2009, 4, e7383. [CrossRef]

8. Knowlton, W.M.; Bifolck-Fisher, A.; Bautista, D.M.; McKemy, D.D. TRPM8, but not TRPA1, is required for neural and behavioral responses to acute noxious cold temperatures and cold-mimetics in vivo. Pain 2010, 150, 340-350. [CrossRef]

9. Colburn, R.W.; Lubin, M.L.; Stone, D.J., Jr.; Wang, Y.; Lawrence, D.; D’Andrea, M.R.; Brandt, M.R.; Liu, Y.; Flores, C.M.; Qin, N. Attenuated cold sensitivity in TRPM8 null mice. Neuron 2007, 54, 379-386. [CrossRef] [PubMed]

10. Gauchan, P.; Andoh, T.; Kato, A.; Kuraishi, Y. Involvement of increased expression of transient receptor potential melastatin 8 in oxaliplatin-induced cold allodynia in mice. Neurosci. Lett. 2009, 458, 93-95. [CrossRef] [PubMed]

11. Nam, J.S.; Cheong, Y.S.; Karm, M.H.; Ahn, H.S.; Sim, J.H.; Kim, J.S. Effects of nefopam on streptozotocin-induced diabetic neuropathic pain inrats. Korean J. Pain 2014, 27, 326-333. [CrossRef] [PubMed]

12. Sarria, I.; Ling, J.; Xu, G.Y.; Gu, J.G. Sensory discrimination between innocuous and noxious cold by TRPM8-expressing DRG neurons ofrats. Mol. Pain 2012, 8, 79. [CrossRef] [PubMed]

13. Dai, Y. TRPs and pain. Semin. Immunopathol. 2016, 38, 277-291. [CrossRef] [PubMed]

14. De Caro, C.; Russo, R.; Avagliano, C.; Cristiano, C.; Calignano, A.; Aramini, A.; Bianchini, G.; Allegretti, M.; Brandolini, L. Antinociceptive effect of two novel transient receptor potential melastatin 8 antagonists in acute and chronic pain models in rat. Br. J. Pharmacol. 2018, 175, 1691-1706. [CrossRef] [PubMed]

15. Proudfoot, C.J.; Garry, E.M.; Cottrell, D.F.; Rosie, R.; Anderson, H.; Robertson, D.C.; Fleetwood-Walker, S.M.; Mitchell, R. Analgesia mediated by the TRPM8 cold receptor in chronic neuropathic pain. Curr.Biol. 2006, 16, 1591-1605. [CrossRef]

16. Dhaka, A.; Earley, T.J.; Watson, J.; Patapoutian, A. Visualizing cold spots: TRPM8-expressing sensory neurons and their projections. J. Neurosci. 2008, 28, 566-575. [CrossRef]

17. Knowlton, W.M.; Daniels, R.L.; Palkar, R.; McCoy, D.D.; McKemy, D.D. Pharmacological blockade of TRPM8 ion channels alters cold and cold pain responses in mice. PLoS ONE 2011, 6, e25894. [CrossRef]

18. Liu, B.; Fan, L.; Balakrishna, S.; Sui, A.; Morris, J.B.; Jordt, S.E. TRPM8 is the principal mediator of menthol-induced analgesia of acute and inflammatory pain. Pain 2013, 154, 2169-2177. [CrossRef]

19. Patel, R.; Gonçalves, L.; Leveridge, M.; Mack, S.R.; Hendrick, A.; Brice, N.L.; Dickenson, A.H. Anti-hyperalgesic effects of a novel TRPM8 agonist in neuropathic rats: A comparison with topical menthol. Pain 2014, 155, 2097-2107. [CrossRef] 
20. Liu, B.; Qin, F. Functional control of cold-and menthol-sensitive TRPM8 ion channels by phosphatidylinositol 4,5-bisphosphate. J. Neurosci. 2005, 25, 1674-1681. [CrossRef]

21. Rohacs, T.; Lopes, C.M.; Michailidis, I.; Logothetis, D.E. PI $(4,5) \mathrm{P}_{2}$ regulates the activation and desensitization of TRPM8 channels through the TRP domain. Nat. Neurosci. 2005, 8, 626-634. [CrossRef] [PubMed]

22. Bertamino, A.; Ostacolo, C.; Ambrosino, P.; Musella, S.; Di Sarno, V.; Ciaglia, T.; Soldovieri, M.V.; Iraci, N.; Fernandez Carvajal, A.; de la Torre-Martinez, R.; et al. Tryptamine-Based Derivatives as Transient Receptor Potential Melastatin Type 8 (TRPM8) Channel Modulators. J. Med. Chem. 2016, 59, 2179-2191. [CrossRef] [PubMed]

23. Takaishi, M.; Uchida, K.; Suzuki, Y.; Matsui, H.; Shimada, T.; Fujita, F.; Tominaga, M. Reciprocal effects of capsaicin and menthol on thermosensation through regulated activities of TRPV1 and TRPM8. J. Physiol. Sci. 2016, 66, 143-155. [CrossRef] [PubMed]

24. Karashima, Y.; Damann, N.; Prenen, J.; Talavera, K.; Segal, A.; Voets, T.; Nilius, B. Bimodal action of menthol on the transient receptor potential channel TRPA1. J. Neurosci. 2007, 27, 9874-9884. [CrossRef] [PubMed]

25. Beccari, A.R.; Gemei, M.; Lo Monte, M.; Menegatti, N.; Fanton, M.; Pedretti, A.; Bovolenta, S.; Nucci, C.; Molteni, A.; Rossignoli, A.; et al. Novel selective, potent naphthyl TRPM8 antagonists identified through a combined ligand- and structure-based virtual screening approach. Sci. Rep. 2017, 7, 10999. [CrossRef] [PubMed]

26. Bertamino, A.; Iraci, N.; Ostacolo, C.; Ambrosino, P.; Musella, S.; Di Sarno, V.; Ciaglia, T.; Pepe, G.; Sala, M.; Soldovieri, M.V.; et al. Identification of a potent tryptophan-based TRPM8 antagonist With in vivo analgesic activity. J. Med. Chem. 2018, 61, 6140-6152. [CrossRef]

27. Bautista, D.M.; Siemens, J.; Glazer, J.M.; Tsuruda, P.R.; Basbaum, A.I.; Stucky, C.L.; Jordt, S.E.; Julius, D. The menthol receptor TRPM8 is the principal detector of environmental cold. Nature 2007, 448, 204-208. [CrossRef]

28. Dhaka, A.; Murray, A.N.; Mathur, J.; Earley, T.J.; Petrus, M.J.; Patapoutian, A. TRPM8 is required for cold sensation in mice. Neuron 2007, 54, 371-378. [CrossRef]

29. Ostacolo, C.; Ambrosino, P.; Russo, R.; Lo Monte, M.; Soldovieri, M.V.; Laneri, S.; Sacchi, A.; Vistoli, G.; Taglialatela, M.; Calignano, A. Isoxazole derivatives as potent transient receptor potentialmelastatintype 8 (TRPM8) agonists. Eur. J. Med.Chem. 2013, 69, 659-669. [CrossRef]

30. Xing, H.; Chen, M.; Ling, J.; Tan, W.; Gu, J.G. TRPM8 mechanism of cold allodynia after chronic nerve injury. J. Neurosci. 2007, 27, 13680-13690. [CrossRef]

31. Mueller-Tribbensee, S.M.; Karna, M.; Khalil, M.; Neurath, M.F.; Reeh, P.W.; Engel, M.A. Differential contribution of TRPA1, TRPV4 and TRPM8 to colonic nociception in mice. PLoS ONE 2015, 10, e0128242. [CrossRef] [PubMed]

32. Caceres, A.I.; Liu, B.; Jabba, S.V.; Achanta, S.; Morris, J.B.; Jordt, S.E. Transient Receptor Potential Cation Channel Subfamily M Member 8 channels mediate the anti-inflammatory effects of eucalyptol. Br. J. Pharmacol. 2017, 174, 867-879. [CrossRef] [PubMed]

33. Descoeur, J.; Pereira, V.; Pizzoccaro, A.; Francois, A.; Ling, B.; Maffre, V.; Couette, B.; Busserolles, J.; Courteix, C.; Noel, J.; et al. Oxaliplatin-Induced Cold Hypersensitivity is Due to Remodelling of Ion Channel Expression in Nociceptors. EMBO Mol. Med. 2011, 3, 266-278. [CrossRef] [PubMed]

34. Kono, T.; Satomi, M.; Suno, M.; Kimura, N.; Yamazaki, H.; Furukawa, H.; Matsubara, K. Oxaliplatin-induced neurotoxicity involves TRPM8 in the mechanism of acute hypersensitivity to cold sensation. Brain Behav. 2012, 2, 68-73. [CrossRef] [PubMed]

35. Brignell, J.L.; Chapman, V.; Kendall, D.A. Comparison of icilin-and cold-evoked responses of spinal neurones, and their modulation of mechanical activity, in a model of neuropathic pain. Brain Res. 2008, 1215, 87-96. [CrossRef] [PubMed]

36. Klein, A.H.; Sawyer, C.M.; Carstens, M.I.; Tsagareli, M.G.; Tsiklauri, N.; Carstens, E. Topical application of L-menthol induces heat analgesia, mechanical allodynia, and a biphasic effect on cold sensitivity in rats. Behav. Brain Res. 2010, 212, 179-186. [CrossRef] [PubMed]

37. Harrington, A.M.; Hughes, P.A.; Martin, C.M.; Yang, J.; Castro, J.; Isaacs, N.J.; Blackshaw, L.A.; Brierley, S.M. A novel role for TRPM8 in visceral afferent function. Pain 2011, 152, 1459-1468. [CrossRef]

38. Baccei, M.L.; Bardoni, R.; Fitzgerald, M. Development of nociceptive synaptic inputs to the neonatal rat dorsal horn: Glutamate release by capsaicin and menthol. J. Physiol. 2003, 549, 231-242. [CrossRef] 
39. Tsuzuki, K.; Xing, H.; Ling, J.; Gu, J.G. Menthol-induced $\mathrm{Ca}^{2+}$ release from presynaptic $\mathrm{Ca}^{2+}$ stores potentiates sensory synaptic transmission. J. Neurosci. 2004, 24, 762-771. [CrossRef]

40. Caterina, M.J. Transient receptor potential ion channels as participants in thermosensation and thermoregulation. Am. J. Physiol. Regul. Integr. Comp. Physiol. 2007, 292, R64-R76. [CrossRef]

41. Patapoutian, A.; Peier, A.M.; Story, G.M.; Viswanath, V. ThermoTRP channels and beyond: Mechanisms of temperature sensation. Nat. Rev. Neurosci. 2003, 4, 529-539. [CrossRef] [PubMed]

42. Rowbotham, M.C.; Nothaft, W.; Duan, W.R.; Wang, Y.; Faltynek, C.; McGaraughty, S.; Chu, K.L.; Svensson, P. Oral and cutaneous thermosensory profile of selective TRPV1 inhibition by ABT-102 in a randomized healthy volunteer trial. Pain 2011, 152, 1192-2000. [CrossRef] [PubMed]

43. Ding, Z.; Gomez, T.; Werkheiser, J.L.; Cowan, A.; Rawls, S.M. Icilin induces a hyperthermia in rats that is dependent on nitric oxide production and NMDA receptor activation. Eur. J. Pharmacol. 2008, 578, 201-208. [CrossRef] [PubMed]

44. Raboisson, P.; Dallel, R. The orofacial formalin test. Neurosci. Biobehav. Rev. 2004, 28, 219-226. [CrossRef] [PubMed]

45. Zuo, X.; Ling, J.X.; Xu, G.Y.; Gu, J.G. Operant behavioral responses to orofacial cold stimuli in rats with chronic constrictive trigeminal nerve injury: Effects of menthol and capsazepine. Mol. Pain 2013, 9, 28. [CrossRef] [PubMed]

46. Bennett, G.J.; Xie, Y.K. A peripheral mononeuropathy in rat that produces disorders of pain sensation like those seen in man. Pain 1988, 33, 87-107. [CrossRef]

47. Wei, E.T. Inhibition of shaking movements in rats by central administration of cholinergic and adrenergic agents. Psychopharmacology 1983, 81, 111-114. [CrossRef]

(C) 2019 by the authors. Licensee MDPI, Basel, Switzerland. This article is an open access article distributed under the terms and conditions of the Creative Commons Attribution (CC BY) license (http://creativecommons.org/licenses/by/4.0/). 